\title{
Lymphatic absorption of $\alpha$-linolenic acid in rats fed flaxseed oil-based emulsion
}

\author{
Leslie Couëdelo ${ }^{1,2}$, Carole Boué-Vaysse ${ }^{2}$, Laurence Fonseca ${ }^{2}$, Emeline Montesinos ${ }^{2}$, \\ Sandrine Djoukitch ${ }^{2}$, Nicole Combe ${ }^{2}$ and Maud Cansell ${ }^{1 *}$ \\ ${ }^{1}$ Université Bordeaux 1, Laboratoire CBMN UMR 5248, F-33405 Talence Cedex, France \\ ${ }^{2}$ ITERG, Unité de Nutrition \& Santé, F-33405 Talence Cedex, France \\ (Received 8 June 2010 - Revised 22 September 2010 - Accepted 8 October 2010 - First published online 17 November 2010)
}

\begin{abstract}
The bioavailability of $\alpha$-linolenic acid (ALA) from flaxseed oil in an emulsified form $v$. a non-emulsified form was investigated by using two complementary approaches: the first one dealt with the characterisation of the flaxseed oil emulsion in in vitro gastrointestinal-like conditions; the second one compared the intestinal absorption of ALA in rats fed the two forms of the oil. The in vitro study on emulsified flaxseed oil showed that decreasing the $\mathrm{pH}$ from 7.3 to 1.5 at the physiological temperature $\left(37^{\circ} \mathrm{C}\right)$ induced instantaneous oil globule coalescence. Some phase separation was observed under acidic conditions that vanished after further neutralisation. The lecithin used to stabilise the emulsions inhibited TAG hydrolysis by pancreatic lipase. In contrast, lipid solubilisation by bile salts (after lipase and phospholipase hydrolysis) was favoured by preliminary oil emulsification. The in vivo absorption of ALA in thoracic lymph duct-cannulated rats fed flaxseed oil, emulsified or non-emulsified, was quantified. Oil emulsification significantly favoured the rate and extent of ALA recovery as measured by the maximum ALA concentration in the lymph $\left(C_{\max }=14 \mathrm{mg} / \mathrm{ml}\right.$ at $3 \mathrm{~h}$ in the emulsion group $v .9 \mathrm{mg} / \mathrm{ml}$ at $5 \mathrm{~h}$ in the oil group; $P<0.05$ ). Likewise, the area under the curve of the kinetics was significantly higher in the emulsion group ( $48 \mathrm{mg} \times \mathrm{h} / \mathrm{ml}$ for rats fed emulsion $v .26 \mathrm{mg} \times \mathrm{h} / \mathrm{ml}$ for rats fed oil; $P<0 \cdot 05)$. On the whole, ALA bioavailability was improved with flaxseed oil ingested in an emulsified state. Data obtained from the in vitro studies helped to partly interpret the physiological results.
\end{abstract}

Key words: Emulsion: Intestinal lipid absorption: Lymphatic lipids: Flaxseed oil: $\alpha$-Linolenic acid bioavailability

The bioavailability of a lipid nutrient present in food depends on complex physico-chemical and enzymatic processes including digestion, intestinal absorption and delivery to all organs for cell lipid requirements ${ }^{(1-3)}$. Several parameters affect the lipid digestion and absorption steps. The influence of the lipid nature ${ }^{(4-8)}$ results, at least partly, from the pancreatic lipase activity due to the TAG structure $^{(7)}$, the inherent resistance of very long PUFA to hydrolysis $^{(4)}$ and the more efficient hydrolysis of shortand medium-chain $\mathrm{TAG}^{(8,9)}$. Fat digestion also depends on the supramolecular lipid structures ingested ${ }^{(10)}$, i.e. liposomes ${ }^{(11)}$ and emulsified oils ${ }^{(12-16)}$. In this latter case, the impact of interfacial composition of the emulsion ${ }^{(13,17,18)}$, as well as the influence of the droplet size of the emulsified lipid phase ${ }^{(12-15)}$, should be taken into account. More recently, it has been demonstrated that the physical state of the TAG also influences the rate and extent of lipid digestion $^{(10,19)}$.
In this context, the aim of the present study was to measure the intestinal absorption of $\alpha$-linolenic acid (ALA) in rats after the administration of flaxseed oil in both emulsified and non-emulsified states. Flaxseed oil was chosen because of its high ALA content. The current French dietary guidelines recommend a daily intake of at least $1 \mathrm{~g}$ of $n$ - 3 ALA for adults, while keeping the linoleic acid:ALA ratio lower than $5^{(20)}$. By comparison, the WHO advises an $n$-3 PUFA intake between $0 \cdot 8$ and $1 \cdot 1 \mathrm{~g}$ of ALA $/ \mathrm{d}$, and the US Dietary Guidelines recommend $1.1 \mathrm{~g}$ for women and $1.6 \mathrm{~g}$ for men. Linoleic acid and ALA are usually consumed in a ratio ranging from 10 to 15 in France, thus making ALA supplementation necessary ${ }^{(21,22)}$. Among various vegetable sources, flaxseed oil nowadays provides the highest amount of ALA (40-45 wt \% of total fatty acids). Several studies have shown the potential to increase the ALA plasma level through flaxseed oil ingestion $^{(23-26)}$. As a result, in July 2006, the French agency

Abbreviations: ALA, $\alpha$-linolenic acid; BS, bile salt; MAG, monoacylglycerol; OD, optical density; O/W, oil-in-water; PL, phospholipid. 
for food, environmental and occupational health safety authorised the introduction of flaxseed oil in foods ${ }^{(27)}$. Recently, flaxseed oil has been marketed as virgin oil ${ }^{(28)}$. With the aim of probing how lipid bioavailability depends on its dispersion state, rats were fed flaxseed oil either in a bulk phase or an oil-in-water $(\mathrm{O} / \mathrm{W})$ emulsion. Soya lecithin was used to stabilise the oil interface. The present study was carried out to determine whether the emulsified state of the lipids influenced ALA lymphatic absorption and, more generally, its bioavailability. In addition, the emulsion stability was characterised under conditions that mimicked those of the gastrointestinal tract in terms of $\mathrm{pH}$ variation, enzyme lipolysis and bile salt (BS) solubilisation.

\section{Experimental methods}

\section{Materials}

Flaxseed oil was supplied by ITERG (Pessac, France). Soya lecithin (Lecimulthin) was kindly provided by Cargill (Baupte, France). The lecithin composition was determined after the separation of different phospholipid (PL) species by two-dimensional TLC using the following solvents: in the first direction, chloroform-acetone-methanol-acetic acid-water (50:20:10:10:5, by vol.), and in the second direction, butanol-acetic acid-water (60:20:20, by vol.) ${ }^{(29)}$. Various diacyl PL and lysophospholipid classes were visualised by exposing the plates to iodine vapour. Different spots were scraped and analysed for total $\mathrm{P}$ determination according to the method used by Ames ${ }^{(30)}$. PL composition of the lecithin is reported in Table 1. Phospholipase $\mathrm{A}_{2}$ from Naja mossambica mossambica, lipase from porcine pancreas, sodium deoxycholate and porcine bile extract were obtained from Sigma (Sigma, St Louis MO, USA). Porcine bile extract was purified from coloured pigments on activated charcoal, as described previously ${ }^{(31)}$. The solvents were of analytical grade.

\section{Emulsion preparation and characterisation}

$\mathrm{O} / \mathrm{W}$ emulsions were prepared at room temperature. The oil phase contained $1 \mathrm{~g}$ of sodium deoxycholate and $20 \mathrm{~g}$ of lecithin per $100 \mathrm{~g}$ of oil. This oil phase was manually dispersed into the aqueous phase to an oil fraction of $45 \mathrm{~g} / 100 \mathrm{~g}$. The coarse $\mathrm{O} / \mathrm{W}$ emulsions obtained were then sheared using an Ultraturax apparatus (IKA, Staufen, Germany), equipped with a generator axis (10 mm S25N-10G; IKA, Staufen, Germany) under a nitrogen flux to

Table 1. Main phospholipid species of the lecithin

\begin{tabular}{lc}
\hline Phospholipids (\%, w/w) & Soya lecithin \\
\hline Phosphatidylcholine & 13.2 \\
Phosphatidylethanolamine & 29.6 \\
Phosphatidylinositol & 24.6 \\
Lysophospholipids & 23.0 \\
Unidentified & 9.6 \\
\hline
\end{tabular}

prevent lipid oxidation. Direct visualisation of the oil droplets just after preparation and under acid stress was carried out using a phase-contrast microscope (Axiovert 135 with a water immersion, $100 \times$ objective; Zeiss, Germany). Mean particle diameter (as evaluated by the volume-weighted average diameter $d_{4,3}$ ) and particle size distribution were determined by static light scattering using a Coulter LS 230 apparatus (Brea, CA, USA).

$\mathrm{O} / \mathrm{W}$ emulsions were exposed to acidic conditions (pH 1.5) using $10 \mathrm{M}-\mathrm{HCl}$. The emulsions were incubated at acid $\mathrm{pH}$, from 0 to $3 \mathrm{~h}$, at $37^{\circ} \mathrm{C}$ and analysed regularly. Neutralisation was carried out by the addition of small volumes of $10 \mathrm{M}-\mathrm{NaOH}$ solution in emulsions previously stored $2 \mathrm{~h}$ under acidic conditions at $37^{\circ} \mathrm{C}$. All experiments were performed under stirring.

\section{Lipid hydrolysis by pancreatic lipase}

The time course of lipase-catalysed hydrolysis of both flaxseed oil and $\mathrm{O} / \mathrm{W}$ emulsions was monitored using a pH-stat (Titroline alpha plus TA10 plus; SCHOTT Instrument, Mainz, Germany) on the basis of protocols described in Hope \& Theimer ${ }^{(32)}$. Experiments were performed in a thermostated bath at $37^{\circ} \mathrm{C}$, and at a $\mathrm{pH}$ of 8 , using a $0.5 \mathrm{M}-\mathrm{NaOH}$ solution for automatic titration. In the case of flaxseed oil, an emulsion was prepared by mixing $40 \mathrm{ml}$ of methocel (3.5\%), $0.6 \mathrm{M}-\mathrm{NaCl}$ solution and $25 \mathrm{ml}$ of oil, under stirring. The hydrolysis reaction was initiated by mixing $10 \mathrm{ml}$ of the previous emulsion with $10 \mathrm{mg}$ of pancreatic lipase in the presence of $2 \mathrm{M}-\mathrm{CaCl}_{2}$. In the case of $\mathrm{O} / \mathrm{W}$ emulsions, the lipase solution was directly added. In another set of experiments, a colipase solution ( $1 \mathrm{mg} / \mathrm{ml})$ was also added to the reaction medium. Lipase activity was calculated from the initial slope of the titration curve and expressed as milliequivalents of fatty acids released per min and per $\mathrm{g}$ of enzyme extract $(\mathrm{mEq} / \mathrm{min}$ per $g$ of enzyme extract). The amount of enzyme and the oil and emulsion concentrations used were chosen to ensure substrate-saturating conditions. In both cases, assays were performed in triplicate.

\section{Lipid solubilisation by bile salts}

Lipid micellisation was performed by BS addition to the hydrolysis products obtained from flaxseed oil in both emulsified and non-emulsified (bulk) states. In the case of bulk flaxseed oil, NEFA and monoacylglycerols (MAG) resulting from pancreatic lipase hydrolysis were mixed with BS. In the case of emulsified flaxseed oil, the PL used to stabilise the emulsion were first subjected to phospholipase $\mathrm{A}_{2}$ hydrolysis (19 units/ml of emulsion) before pancreatic lipase addition. In this instance, NEFA and MAG from lipase hydrolysis, and NEFA and lysophospholipids from phospholipase $\mathrm{A}_{2}$ hydrolysis were solubilised.

The lipid-BS mixtures were prepared by adding $10 \mathrm{ml}$ of a concentrated BS solution (concentrations ranging 
from 5 to $70 \mathrm{~mm}$, considering an average molecular weight for BS of $480 \mathrm{~g} / \mathrm{mol}$ ) to the hydrolysed lipids (ranging from 3 to $50 \mathrm{mg}$, i.e. concentrations ranging from 0.5 to $5 \mathrm{~mm}$, considering an average molecular weight for both TAG and PL of $775 \mathrm{~g} / \mathrm{mol}$ ). Micellisation by BS was followed by measuring the turbidity at $400 \mathrm{~nm}$. Turbidity measurements (optical density (OD) at $400 \mathrm{~nm}$ ) were performed in a thermostated cell support using a Perkin Elmer lambda Bio 20 spectrophotometer (Waltham, MA, USA). After stirring, the mixtures were allowed to equilibrate until stable turbidity values were obtained. For each lipid concentration ([lip]tot), a solubilisation curve was obtained by plotting the evolution of OD as a function of total BS concentration ([BS]tot). The solubilisation point, corresponding to the BS amount required to completely solubilise the lipids into mixed micelles, was determined as the point at which further addition of BS only slightly affected the suspension turbidity. In practice, this point corresponded to an OD approximately equal to zero, as in Lichtenberg ${ }^{(33)}$. At this solubilisation point, the concentration of BS molecules not associated with the lipids ([BS]bulk) and the molecular ratio of BS to lipid in the mixed micelles ([BS:lip]mic) were determined by the following equation ${ }^{(34)}$ :

$$
[\text { BS }] \text { tot }=[\text { BS }] \text { bulk }+[\text { BS:lip]mic } \times[\text { lip]tot. }
$$

Using linear regression analysis, [BS]bulk was deduced from the intercept of the extrapolated curve with the ordinate axis, and [BS:lip]mic was deduced from the slope. Solubilisation was performed at 25 and $37^{\circ} \mathrm{C}$ on hydrolysis products derived from flaxseed oil in the bulk and emulsified states.

\section{Animals, surgical procedures and lymph analysis}

Male Wistar rats (8 weeks old, body weight 300-350 g) were obtained from Elevage Janvier (St-Berthevin, France) and were randomly assigned to one of the dietary groups. The study was conducted in accordance with European Community Council Directives (861609/EEC). All experiments conformed to the Guidelines for the Handling and Training of Laboratory Animals. Rats were housed for at least $3 \mathrm{~d}$ before the experiment in a controlled environment, with constant temperature and humidity, and with free water and food access. Two lipid formulas based on flaxseed oil were used for the experiments (Table 2). Rats were fed a fat-free diet (Epinay, France) and had free access to water $24 \mathrm{~h}$ before the surgery. For collecting the lymph, a polyethylene catheter (inner diameter $0.86 \mathrm{~mm}$, outer diameter $1.27 \mathrm{~mm}$; Biotrol, Paris, France) was inserted into the main mesenteric lymph duct of each rat placed under ketamine/xylazine anaesthesia (100 and $10 \mu \mathrm{g} / \mathrm{g}$ of body weight), as described in Bollman et $a l .{ }^{(35)}$ and Combe et al. ${ }^{(36)}$. After the surgery, rats were placed in individual restraining cages, in a warm environment, with tap water freely available. A few hours later,
Table 2. Main fatty acid profile of the dietary lipids and their intramolecular distribution in TAG

\begin{tabular}{|c|c|c|c|c|}
\hline \multirow[b]{2}{*}{ Fatty acids* } & \multicolumn{2}{|c|}{ Flaxseed oil } & \multicolumn{2}{|c|}{ Flaxseed oil emulsion $†$} \\
\hline & $\begin{array}{l}\text { TAG } \\
\text { (wt \%) }\end{array}$ & $\begin{array}{c}\text { sn-2 MAGł } \\
(\mathrm{mol} \%)\end{array}$ & $\begin{array}{l}\text { Soya lecithin } \\
\text { (wt \%) }\end{array}$ & $\begin{array}{c}\text { Total lipids } \\
\text { (wt \%) }\end{array}$ \\
\hline $16: 0$ & $5 \cdot 1$ & 7.4 & 22.5 & 5.4 \\
\hline 18:0 & 4.0 & $3 \cdot 8$ & 3.4 & 4.0 \\
\hline $18: 1 n-9$ & $18 \cdot 5$ & $51 \cdot 8$ & 11.7 & $19 \cdot 0$ \\
\hline $18: 2 n-6$ & $15 \cdot 5$ & $49 \cdot 2$ & $55 \cdot 3$ & $19 \cdot 6$ \\
\hline $18: 3 n-3$ & $46 \cdot 0$ & 28.4 & 4.2 & $47 \cdot 2$ \\
\hline $18: 3 n-6$ & 0.3 & 13.4 & $0 \cdot 1$ & 0.1 \\
\hline Trans-18: $3 n-3$ & $6 \cdot 3$ & $31 \cdot 6$ & 0.0 & $6 \cdot 7$ \\
\hline Others§ & $2 \cdot 6$ & & $1 \cdot 2$ & 1.9 \\
\hline$\Sigma$ SFA & $10 \cdot 0$ & & $26 \cdot 8$ & 9.9 \\
\hline$\Sigma$ MUFA & $20 \cdot 8$ & & $13 \cdot 4$ & $20 \cdot 1$ \\
\hline$\sum n-3$ PUFA & $46 \cdot 0$ & & 4.3 & $47 \cdot 2$ \\
\hline$\sum n-6$ PUFA & $16 \cdot 0$ & & 55.5 & $19 \cdot 7$ \\
\hline$\Sigma$ TFA & 6.9 & & 0.1 & 6.9 \\
\hline$n-6: n-3$ & 0.35 & & $12 \cdot 91$ & 0.41 \\
\hline
\end{tabular}

sn-2 MAG, sn-2 monoacylglycerol; TFA, trans-fatty acid.

* Fatty acid composition represents the mean of two measurements.

† Flaxseed oil was emulsified using $8 \%$ soya lecithin.

¥ The fatty acid composition of sn-2 MAG of flaxseed oil TAG was determined after pancreatic lipase hydrolysis followed by isolation and analysis of monoacylglycerols. Results are expressed in mol\% corresponding to the distribution of each fatty acid in the internal position of TAG.

$\S$ Others represent the sum of the fatty acids that each contributes to $<1 \mathrm{~g} / 100 \mathrm{~g}$.

$0 \cdot 3 \mathrm{~g}$ of flaxseed oil, either as bulk oil or $\mathrm{O} / \mathrm{W}$ emulsion, were administered through a gastric feeding tube, followed by $0.5 \mathrm{ml}$ of water. The amounts of total fatty acids and ALA per rat were, for the bulk-phase group, 230 and $103 \mathrm{mg}$, respectively, and, for the emulsion group, 260 and $104 \mathrm{mg}$, respectively. Lymph was collected for $24 \mathrm{~h}$ with fractionation in tared tubes maintained in an ice bath. During the collection period, the lymph flow averaged $0.30($ sem 0.03$) \mathrm{ml} / \mathrm{h}$. The total lipid contents of chylomicrons were immediately analysed. At least eight cannulated rats were used for each studied lipid ingestion condition.

Lipids from lymph samples were transmethylated according to the method of Lepage \& Roy ${ }^{(37)}$. Trimyristolein was added as an internal standard for TAG fatty acid quantification. Fatty acid methyl esters were analysed by GC on a BPX 70 capillary column (60 m long, $0.25 \mu \mathrm{m}$ film, $0.25 \mathrm{~mm}$ inner diameter (SGE, Victoria, Australia), $\mathrm{H}_{2}$ as a carrier gas and split ratio of 1:80). The GC system consisted of a gas chromatograph (HP 4890; Hewlett Packard, Palo Alto, CA, USA) equipped with a flame ionisation detector maintained at $280^{\circ} \mathrm{C}$. The injector temperature was $250^{\circ} \mathrm{C}$. The column temperature was increased from 150 to $200^{\circ} \mathrm{C}\left(1 \cdot 3^{\circ} \mathrm{C} / \mathrm{min}\right)$, maintained at $200^{\circ} \mathrm{C}$ for $20 \mathrm{~min}$, increased from 200 to $235^{\circ} \mathrm{C}\left(10^{\circ} \mathrm{C} / \mathrm{min}\right)$ and held at $235^{\circ} \mathrm{C}$ for $20 \mathrm{~min}$. Data were collected and integrated by a Chromjet SP 4400 integration system (Spectra-Physics, Irvine, CA, USA). Fatty acids from Sigma France (St Quentin Fallavier, France) and natural extracts of known composition were used as standards for column calibration. The variation in peak area between injections was less than $2 \%$. 
The intramolecular fatty acid distribution in TAG of dietary flaxseed oil and lymph chylomicrons was determined through lipase hydrolysis according to Desnuelle ${ }^{(38)}$ and Entressangles et al. $^{(39)}$. The resulting 2-MAG and 1,3-diacylglycerols were separated by TLC using hexanediethyl ether-formic acid (70:30:1, by vol.) as a developing solvent ${ }^{(39)}$. Respective fractions were transmethylated, and fatty acid methyl esters were analysed by GC, as described previously. The proportion of ALA in the $s n-2$ position of TAG was obtained by the following equation:

$$
\% \operatorname{ALA}(s n-2)=\frac{\% \operatorname{ALA}(2-\mathrm{MAG}) \times 100}{\% \operatorname{ALA}(\mathrm{TAG}) \times 3} .
$$

\section{Statistical analysis}

Data are expressed as means with their standard errors. When only two independent groups of data were compared (solubilisation data and kinetic study), the parametric Student's $t$ test was used. The area under the curve was calculated according to the trapezoidal method, and the data were compared with the Mann-Whitney test. Differences were considered significant at $P<0 \cdot 05$. The statistical significance of differences in the fatty acid compositions of chylomicron TAG between the three dietary conditions (fasted, bulk flaxseed oil and emulsion) was analysed by one-way ANOVA. $V_{\max }$ values obtained with different hydrolysis conditions were analysed by two-way ANOVA. These analyses included Dunnett's multiple comparison procedure and Tukey's honestly significant difference procedure. Only when two of the above tests showed significance at the $P<0.05$ level were the differences judged to be significant.

\section{Results}

\section{Emulsion behaviour under acid conditions}

The $\mathrm{O} / \mathrm{W}$ emulsions were characterised in terms of droplet size distribution. The mean diameter of the droplets was found to be $4.9 \mu \mathrm{m}$, with a distribution ranging from 0.8 to $15 \mu \mathrm{m}$ as confirmed by optical microscopy (Fig. 1(a)). When the medium was acidified $(\mathrm{pH} 1.5)$ in order to mimic gastrointestinal tract conditions, the mean diameter increased up to $12 \cdot 2 \mu \mathrm{m}$ because of droplet coalescence (Fig. 1(b)). Some phase separation was observed under this acidic condition during a $3 \mathrm{~h}$ storage period. In the physiological digestion process, emulsions stayed for approximately $2-3 \mathrm{~h}$ under acidic conditions (comparable to the human stomach) before returning to a neutral environment (comparable to the human intestine). To mimic this shift in $\mathrm{pH}$, an emulsion sample previously stored at $\mathrm{pH} 1.5$ for $2 \mathrm{~h}$ at $37^{\circ} \mathrm{C}$ was further neutralised $(\mathrm{pH} 7 \cdot 3)$. This resulted in a slight increase in the mean diameter, although no phase separation was observed in the sample (Fig. 1(c)). The size distribution did not vary for at least $24 \mathrm{~h}$ (results not shown).
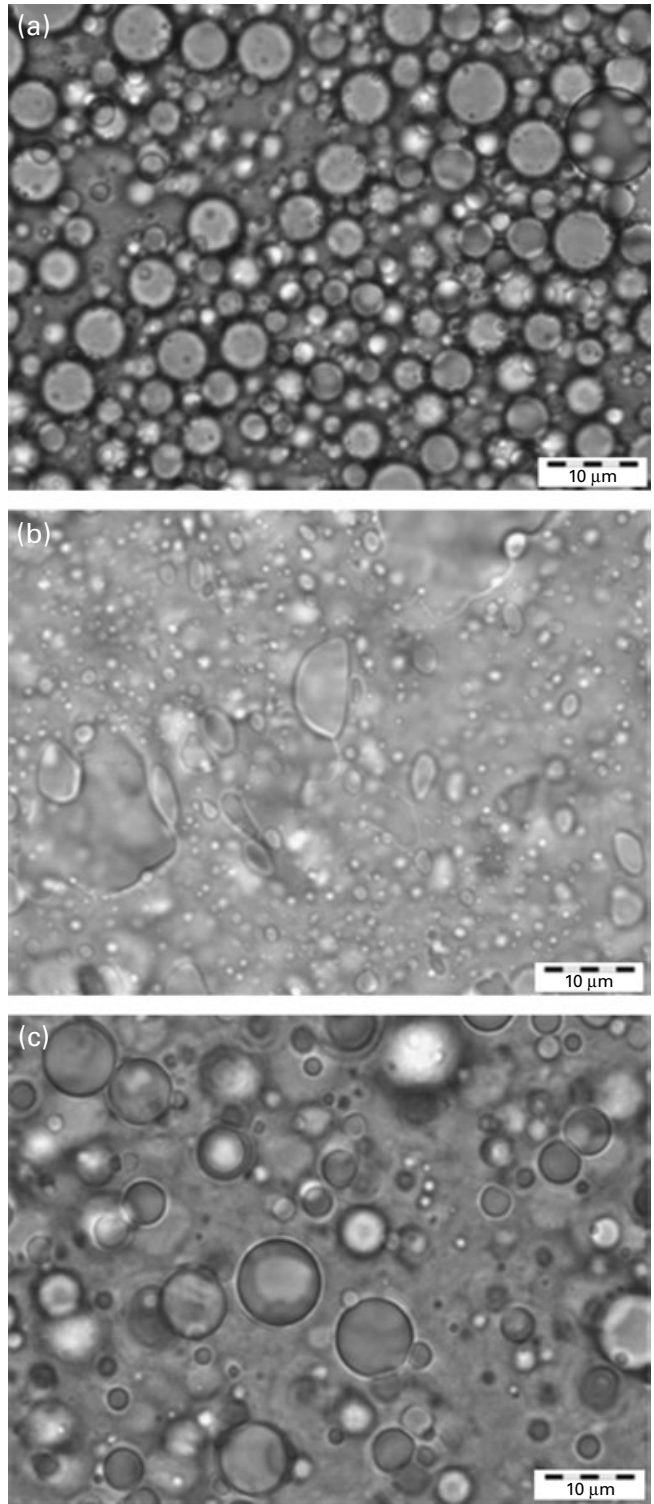

Fig. 1. Microscopy observation $(100 \times)$ of flaxseed emulsions stabilised by soya lecithin: (a) just after preparation; (b) in acid conditions $(\mathrm{pH} \mathrm{1.5,}$ $\left.10 \mathrm{~min}, 37^{\circ} \mathrm{C}\right)$; (c) in neutral conditions ( $\mathrm{pH} \mathrm{7.3)}$ after an incubation of $2 \mathrm{~h}$ at $\mathrm{pH} 1.5\left(37^{\circ} \mathrm{C}\right)$.

\section{Lipid solubilisation by bile salts}

To mimic lipid transfer from the stomach to the intestine, bulk oil and emulsions were exposed to pancreatic lipase with or without phospholipase $\mathrm{A}_{2}$ before $\mathrm{BS}$ addition. The solubilisation process was followed by variations in turbidity measured as a function of BS addition. Almost zero turbidity levels corresponding to mixed micelles at equilibrium were obtained after $36 \mathrm{~h}$ (results not shown), indicating that equilibrium was slowly reached when BS were added to the digestion products of either bulk oil or emulsions. Fig. 2 presents typical solubilisation curves obtained for various lipid concentrations in emulsions. Lipid micellisation was achieved when a drastic decrease in OD was observed. The complex evolutions of the OD suggested that the lipid-surfactant structures underwent 


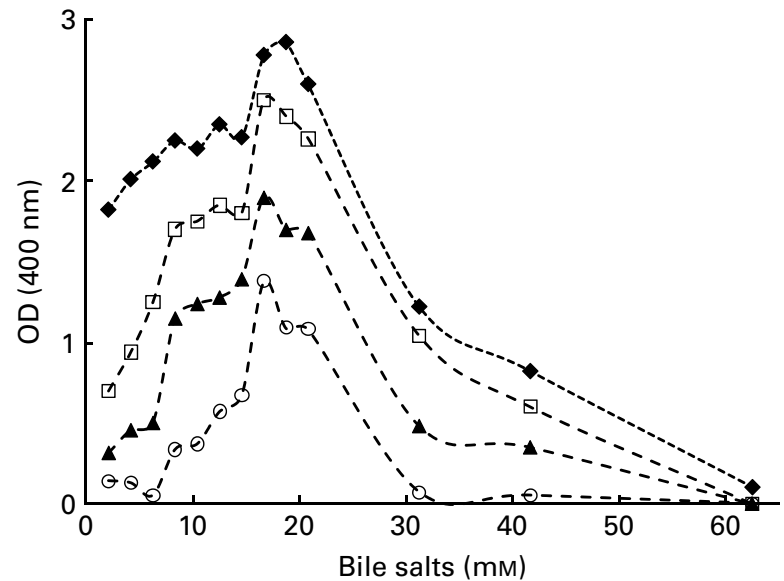

Fig. 2. Dependence of turbidity on the bile salt concentration in equilibrated NEFA-lysophospholipid-monoacylglycerol-bile salt-mixed dispersions containing constant lipid levels and varying levels of bile salts. The samples were made by a series of dilutions of the lipid aggregates after phospholipase $\mathrm{A}_{2}$ followed by pancreatic lipase hydrolysis with various bile salt solutions ([lip]tot $=4.2(\diamond), 2.1(\square), 1.0(\mathbf{\Lambda})$ and $0.5(\bigcirc) \mathrm{mm})$. [lip]tot, lipid concentration. OD, optical density.

size and/or shape variations, as already reported for the solubilisation of other colloidal structures such as liposomes ${ }^{(34,40,41)}$. Varying the lipid concentration made it possible to calculate two parameters that fully describe the solubilisation process, i.e. [BS]bulk and [BS:lip]mic. The results for mixed micelles at equilibrium are reported in Table 3. Irrespective of the initial lipid system and/or of the temperature, [BS]bulk values were well above the critical micellar concentration of the main bile acids present in bile ( $11 \mathrm{~mm}$ for cholic acid and $3 \mathrm{~mm}$ for deoxycholic acid) ${ }^{(42)}$, suggesting that, at the micellisation point and thereafter, mixed lipid-BS micelles and pure BS micelles coexisted. The composition of mixed micelles consisting of fatty acids, MAG and BS was hardly influenced by an increase in temperature up to $37^{\circ} \mathrm{C}$. This may be related to the fact that, at $25^{\circ} \mathrm{C}$, acyl chains were already

Table 3. Bile salt:lipid molecular ratio in mixed micelles ([BS:lip]mic) at equilibrium and the corresponding bile salt concentration in the continuum medium ([BS]bulk) as a function of temperature and the initial lipid system (oil and emulsion)

(Mean values with their standard errors)*

\begin{tabular}{|c|c|c|c|c|c|}
\hline \multirow[b]{2}{*}{ Lipid system } & \multirow[b]{2}{*}{ Temperature $\left({ }^{\circ} \mathrm{C}\right)$} & \multicolumn{2}{|c|}{ [BS:lip]mic } & \multicolumn{2}{|c|}{ [BS]bulk (mM) } \\
\hline & & Mean & SEM & Mean & SEM \\
\hline Oilt & 25 & $6.0 \ddagger$ & $2 \cdot 1$ & $36 \cdot 8$ & $7 \cdot 0$ \\
\hline Oil & 37 & 5.5 & $2 \cdot 0$ & $35 \cdot 0$ & $7 \cdot 1$ \\
\hline Emulsion§ & 25 & $2 \cdot 5 \|$ & $1 \cdot 3$ & $31 \cdot 8$ & $5 \cdot 1$ \\
\hline Emulsion & 37 & $4 \cdot 6$ & $2 \cdot 1$ & $22 \cdot 8$ & $7 \cdot 1$ \\
\hline
\end{tabular}

* Values represent the mean of at least five independent experiments for each lipid system (oil and emulsion) and temperature $\left(25\right.$ and $\left.37^{\circ} \mathrm{C}\right)$.

† Oil was subjected to pancreatic lipase before bile salt addition.

$\ddagger$ Mean values were significantly different from those of the emulsion system $(P<0.05)$.

$\S$ Emulsion was subjected to phospholipase $\mathrm{A}_{2}$ and pancreatic lipase before bile salt addition.

$\|$ Mean values were significantly different from the experiment performed at $37^{\circ} \mathrm{C}$ $(P<0.05)$. in the liquid state. In the present study, increasing the temperature from 25 to $37^{\circ} \mathrm{C}$ may only modify the solubility of BS in the aqueous phase and/or the partition of the surfactant between the aqueous phase and the micelles. In the case of flaxseed emulsions, the resulting mixed micelles contained lysophospholipids in addition to fatty acids, MAG and BS. At $25^{\circ} \mathrm{C}$, lysophospholipids significantly decreased the [BS:lip]mic value due to their surface-active properties (Table 3 ). Increasing the temperature from 25 to $37^{\circ} \mathrm{C}$ led to a significant increase in the [BS:lip]mic value (Table 3). This suggested a lower solubility of BS monomers at the physiological temperature. No phase transition of lysophospholipids occurred because they were already in a liquid-crystalline phase at $25^{\circ} \mathrm{C}$. Increasing the temperature may lead to the coexistence of different types of micelles. Indeed, with regard to lecithin/BS-mixed micelles, simple BS micelles may coexist in varying proportions with mixed micelles, depending on the type of BS, the [lecithin]:[BS] ratio and the temperature ${ }^{(43)}$.

\section{Oil and emulsion hydrolysis by pancreatic lipase}

Pancreatic lipase catalyses the hydrolysis of $s n-1$ and $s n-3$ fatty acyl ester bonds of TAG to produce 2-MAG and fatty acids. The catalytic behaviour was studied on bulk oil and emulsions stabilised by lecithin. All experiments were performed with a lipid:enzyme ratio greater than $10^{5}$ that ensured a saturating concentration of substrate (results not shown). Under these conditions, the initial rate per $g$ of enzyme extract corresponding to the maximal activity of the enzyme $\left(V_{\max }\right)$ was calculated from curves (Fig. 3, inset). The $V_{\max }$ value obtained with bulk oil $(2 \cdot 2(\operatorname{sem} 0 \cdot 7) \mathrm{mEq} / \mathrm{min}$ per $\mathrm{g}$ of enzyme extract) was significantly higher than that measured in the emulsion $(0.7$ (SEM 0.2$) \mathrm{mEq} / \mathrm{min}$ per $\mathrm{g}$ of enzyme extract; $P<0.05)$.

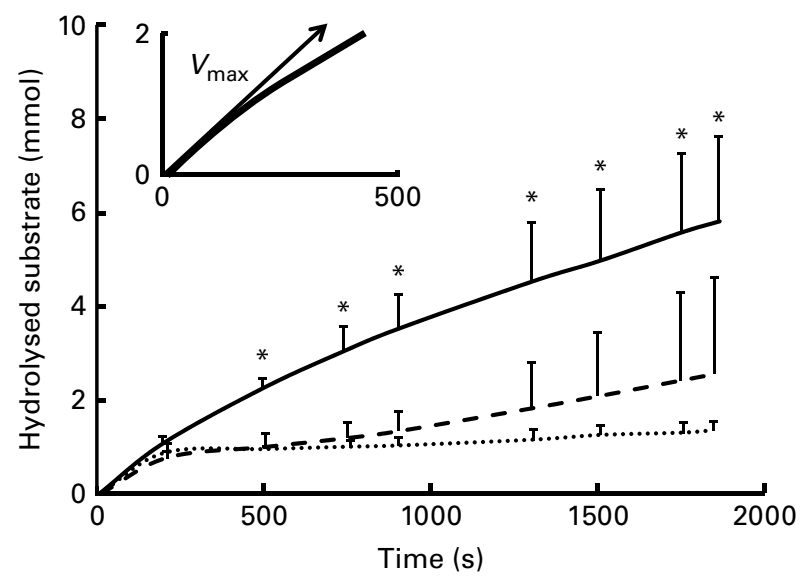

Fig. 3. Time course for a typical hydrolysis of oil by pancreatic lipase (-), of oil-in-water emulsion stabilised by lecithin by pancreatic lipase $(--)$ and by pancreatic lipase and colipase $(\cdots \cdots)$. Inset: the total velocity $\left(V_{\max }\right)$ was determined as extrapolation of the linear line to zero abscissa. All experiments were performed at least five times. ${ }^{*}$ Mean values were significantly different at a time point $(P<0.05)$. 
The addition of colipase to this emulsified system did not increase lipase activity, suggesting that, in vitro, colipase could not prevent pancreatic lipase inhibition by PL (Fig. 3).

\section{Lymphatic recovery of $\alpha$-linolenic acid}

Because lymph flow did not show any significant difference between rats throughout the kinetic study, the two treated groups were compared with regard to fatty acid concentration in the lymph. At $24 \mathrm{~h}$ after feeding, the total fatty acid concentration in the lymph was twice as high in the emulsion group as in the oil group $(32.5 v .14 .5 \mathrm{mg} / \mathrm{ml}$ of lymph; $P<0.001)$. This tendency was also observed for ALA $(8.0 \mathrm{mg} / \mathrm{ml}$ of lymph in the emulsion group, compared with $3.5 \mathrm{mg} / \mathrm{ml}$ of lymph in the oil group; $P<0.05)$. The rate and total extent of ALA absorption at the intestinal site are illustrated in Fig. 4 for up to $6 \mathrm{~h}$ after feeding. The rate of ALA absorption was similar for both groups in the first $2 \mathrm{~h}$. After $3 \mathrm{~h}$, ALA recovery in the lymph of the emulsion group was significantly higher than that of the bulk-phase group $(14.0 \quad v .6 .5 \mathrm{mg} / \mathrm{ml}$, respectively). Moreover, the maximum ALA concentration $\left(C_{\max }\right)$ was obtained sooner, and to a significantly greater extent in the emulsion group compared with the bulk-phase group (Table 4). Likewise, the area under the curve that estimates the intestinal bioavailability of ALA was significantly higher for rats fed emulsified flaxseed oil (Fig. 4, inset; Table 4).

Fatty acid composition of flaxseed oil and the intramolecular fatty acid distribution in TAG are shown in Table 2. In bulk flaxseed oil, ALA, the major fatty acid, was evenly distributed between the three positions of the TAG molecules. The two other main fatty acids, oleic acid $(18: 1)$ and linoleic acid (18:2), were mainly esterified in the internal position. The fatty acid composition of

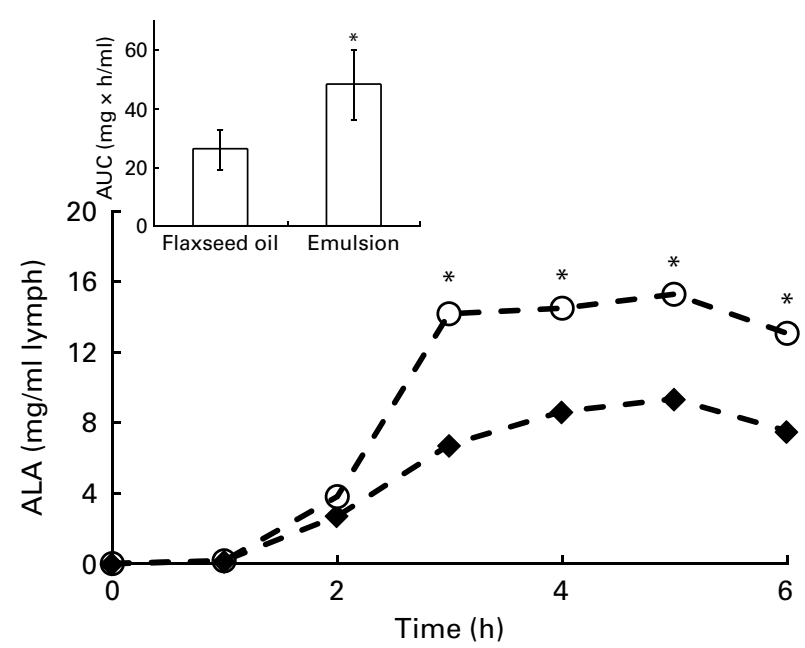

Fig. 4. Time-course concentration of $\alpha$-linolenic acid (ALA) in chylomicrons for the oil $(\diamond)$ and emulsion $(O)$ rat groups. Values are means of at least eight rats for each lipid system, at each time point. ${ }^{\star}$ Mean values were significantly different at a time point $(P<0.05)$. Inset represents the area under the curve (AUC) for the two rat groups.
Table 4. Maximum $\alpha$-linolenic acid concentration $\left(C_{\max }\right)$, time required to reach $C_{\max }\left(T_{\max }\right)$ and area under the curve (AUC) in the lymph of rats fed flaxseed oil in the bulk phase or in the oil-in-water emulsion

(Mean values with their standard errors, $n$ 8)

\begin{tabular}{|c|c|c|c|c|}
\hline & \multirow[b]{2}{*}{$C_{\max }(\mathrm{mg} / \mathrm{ml})^{\star}$} & \multirow[b]{2}{*}{$T_{\max }(\mathrm{h})$} & \multicolumn{2}{|c|}{$\mathrm{AUC}(\mathrm{mg} \times \mathrm{h} / \mathrm{ml})$} \\
\hline & & & Mean & SEM \\
\hline Oil & 9 & 5 & 26 & 7 \\
\hline Emulsion & $14 \dagger$ & 3 & $48 \dagger$ & 12 \\
\hline
\end{tabular}

* Lipid ingestion by rats corresponded to $0.3 \mathrm{~g}$ in the form of flaxseed oil in the bulk phase or emulsified. Chylomicrons were collected for $24 \mathrm{~h}$ from eight animals, and the lipid fractions were extracted. Following separation by TLC, TAG was analysed for fatty acid composition by GC.

$\dagger$ Mean values were significantly different $(P<0.05)$.

lymphatic chylomicron TAG and their intramolecular fatty acid distribution following administration of flaxseed oil as a bulk phase or as an emulsion were examined (Table 5). The fatty acid composition of chylomicron TAG of both rat groups mainly reflected the fatty acid profile of the dietary lipid source. As expected, feeding rats with bulk flaxseed oil or with an emulsion increased the proportion of ALA in the lymph compared with fasted rats. A significant decrease in the proportion of endogenous fatty acids, palmitic acid (16:0) and arachidonic acid (20:4), was observed in the lymph, mainly due to a dilution of these fatty acids in TAG as a consequence of their low proportions of dietary lipids. The proportion of ALA in the $s n-2$ position of chylomicron TAG was similar in the three dietary groups (Table 5).

\section{Discussion}

Among various vegetable oils, flaxseed oil is one of the richest sources of ALA. Several studies in human subjects have already demonstrated that flaxseed oil intake leads to an increase in ALA levels in the plasma ${ }^{(23,25)}$ and an enrichment in ALA of erythrocyte total $\mathrm{PL}^{(23,44)}$. Moreover, flaxseed oil consumption has been associated with significant health benefits thanks to an improvement of biomarkers of cardiovascular risk ${ }^{(23,26,45)}$ and of inflammation $^{(24,26)}$. On the one hand, basic information about ALA bioavailability from flaxseed oil is still unavailable in order to understand its biological efficiency. On the other hand, improving the bioaccessibility of ALA from the food matrix is a potential strategy for providing additional n-3 PUFA.

In the present study, we compared the metabolic fate of flaxseed oil delivered either as a bulk phase or as an emulsion on lymphatic absorption. We clearly demonstrated that TAG were more efficiently absorbed when provided as an emulsion rather than as a bulk phase. As a result, fatty acid and ALA enrichment in chylomicrons was greater $\left(C_{\max }\right)$ and faster $\left(T_{\max }\right)$ in rats fed emulsified oil than in rats fed bulk oil. These results are in agreement with others studies performed either on animal models ${ }^{(13,46)}$ or on human subjects ${ }^{(16)}$. These studies have suggested 
Table 5. Main fatty acid composition and distribution of chylomicron TAG in the rat lymph resulting from oil in the bulk phase or oil-in-water (O/W) emulsion ingestion $24 \mathrm{~h}$ after feeding

(Mean values with their standard errors, $n 8$ )

\begin{tabular}{|c|c|c|c|c|c|c|c|c|c|}
\hline \multirow[b]{4}{*}{ Fatty acids } & \multicolumn{9}{|c|}{ Chylomicrons* } \\
\hline & \multicolumn{3}{|c|}{ Fasted rats } & \multicolumn{3}{|c|}{ Oil } & \multicolumn{3}{|c|}{$\mathrm{O} / \mathrm{W}$ emulsion } \\
\hline & \multicolumn{2}{|c|}{ TAG† (wt \%) } & \multirow{2}{*}{$\begin{array}{c}\text { sn-2 MAG } \ddagger(\mathrm{mol} \%) \\
\text { Mean }\end{array}$} & \multicolumn{2}{|c|}{ TAG (wt \%) } & \multirow{2}{*}{$\begin{array}{c}\text { sn-2 MAG (mol \%) } \\
\text { Mean }\end{array}$} & \multicolumn{2}{|c|}{ TAG (wt \%) } & \multirow{2}{*}{$\begin{array}{c}\text { sn-2 MAG (mol\%) } \\
\text { Mean }\end{array}$} \\
\hline & Mean & SEM & & Mean & SEM & & Mean & SEM & \\
\hline $16: 0$ & $24 \cdot 1^{a}$ & $2 \cdot 7$ & $47 \cdot 6$ & $12 \cdot 1^{\mathrm{b}}$ & 0.7 & 47.4 & $12 \cdot 2^{\mathrm{b}}$ & $0 \cdot 8$ & 39.1 \\
\hline $18: 0$ & $9 \cdot 4^{\mathrm{a}}$ & 1.0 & $10 \cdot 6$ & $5 \cdot 7^{b}$ & 0.5 & $24 \cdot 3$ & $4 \cdot 8^{b}$ & 0.5 & $20 \cdot 1$ \\
\hline $16: 1 n-7$ & $3 \cdot 2^{\mathrm{a}}$ & 0.5 & 23.6 & $1.5^{\mathrm{b}}$ & 0.8 & $24 \cdot 3$ & $1.5^{\mathrm{b}}$ & 0.8 & $19 \cdot 2$ \\
\hline $18: 1 n-9$ & $14 \cdot 4^{\mathrm{a}}$ & $1 \cdot 0$ & 33.8 & $17 \cdot 8^{\mathrm{b}}$ & 0.3 & $46 \cdot 9$ & $18 \cdot 7^{\mathrm{b}}$ & 0.7 & $46 \cdot 4$ \\
\hline $18: 1 n-7$ & $5 \cdot 5^{\mathrm{a}}$ & 0.2 & $16 \cdot 5$ & $2 \cdot 2^{b}$ & 0.4 & $23 \cdot 1$ & $2 \cdot 2^{b}$ & 0.4 & 20.9 \\
\hline $18: 2 n-6$ & $19 \cdot 1$ & 2.5 & $40 \cdot 3$ & $17 \cdot 1$ & $4 \cdot 1$ & $41 \cdot 8$ & $18 \cdot 8$ & $2 \cdot 1$ & $42 \cdot 5$ \\
\hline $18: 3 n-3$ & $0.6^{a}$ & 0.0 & $15 \cdot 8$ & $32 \cdot 1^{\mathrm{b}}$ & 1.3 & $17 \cdot 7$ & $30 \cdot 5^{\mathrm{b}}$ & $4 \cdot 1$ & $23 \cdot 1$ \\
\hline $20: 4 n-6$ & $11.9^{\mathrm{a}}$ & 0.3 & 37.4 & $2 \cdot 3^{\mathrm{b}}$ & 0.2 & $50 \cdot 2$ & $1.9^{\mathrm{b}}$ & 0.5 & 59.0 \\
\hline $22: 5 n-3$ & $0.7^{\mathrm{a}}$ & 0.4 & 0.3 & $0.2^{\mathrm{b}}$ & 0.0 & 9.0 & $0.2^{\mathrm{b}}$ & 0.1 & $11 \cdot 2$ \\
\hline $22: 6 n-3$ & $2 \cdot 4^{\mathrm{a}}$ & 0.4 & $13 \cdot 3$ & $0.9^{b}$ & 0.1 & $15 \cdot 5$ & $0.5^{\mathrm{b}}$ & 0.2 & $26 \cdot 7$ \\
\hline$\Sigma$ SFA & $36 \cdot 6^{\mathrm{a}}$ & $1 \cdot 1$ & & $19 \cdot 2^{b}$ & $3 \cdot 2$ & & $18 \cdot 7^{\mathrm{b}}$ & $4 \cdot 1$ & \\
\hline$\Sigma$ MUFA & $26 \cdot 6^{\mathrm{a}}$ & $2 \cdot 1$ & & $22 \cdot 7^{b}$ & 1.4 & & $23 \cdot 6^{\mathrm{b}}$ & 1.6 & \\
\hline$\sum n-3$ PUFA & $4 \cdot 0^{\mathrm{a}}$ & 0.8 & & $33.4^{\mathrm{b}}$ & 1.2 & & $31 \cdot 3^{\mathrm{b}}$ & $2 \cdot 8$ & \\
\hline$\sum n-6$ PUFA & $32 \cdot 2^{a}$ & $2 \cdot 0$ & & $20 \cdot 1^{\mathrm{b}}$ & $3 \cdot 1$ & & $21 \cdot 3^{b}$ & $3 \cdot 1$ & \\
\hline$\Sigma T F A$ & $0.3^{\mathrm{a}}$ & 0.2 & & $4 \cdot 6^{\mathrm{b}}$ & 0.3 & & $4 \cdot 8^{\mathrm{b}}$ & 0.3 & \\
\hline$n-6: n-3$ & $8.05^{a}$ & 1.08 & & $0.60^{\mathrm{b}}$ & 0.04 & & $0.68^{b}$ & 0.10 & \\
\hline
\end{tabular}

sn-2 MAG, sn-2 monoacylglycerol; TFA, trans-fatty acid.

a,b Mean values within a row with unlike superscript letters were significantly different for lymphatic fatty acid wt \% $(P<0.05)$.

* Lipid ingestion by rats corresponded to $0.3 \mathrm{~g}$ in the form of flaxseed oil in the bulk phase or emulsified. Chylomicrons were collected for $24 \mathrm{~h}$ from eight animals, and the lipid fractions were extracted. Following separation by TLC, TAG was analysed for fatty acid composition by GC.

$\dagger$ The data represent the average of three different determinations.

¥ The fatty acid composition of sn-2 MAG of flaxseed oil and chylomicron TAG was determined after pancreatic lipase hydrolysis followed by isolation and analysis of MAG. The sn-2 MAG analysis was performed on pooled samples of the lymph of eight rats. Results are expressed in mol \% corresponding to the distribution of each fatty acid in the internal position of TAG.

that PL from egg phosphatidylcholine $e^{(13,47)}$ or soya phosphatidylcholine ${ }^{(13)}$ could enhance lipid intestinal absorption in rats. Nishimukai et al. ${ }^{(13)}$ have also shown that the enhancement of lipid output in the lymph was highly related to the TAG:PL ratio used in the dietary formulation.

The digestion process implies a hydrolysis step by lipolytic enzymes including pancreatic lipase that operates at the oil-water interface. Both the nature of the lipids present at this interface and the curvature of the interface could modulate enzyme activity. Indeed, studies based on in vitro digestion of emulsified lipids coated with various emulsifiers have shown that PL facilitated access to emulsified fats compared with other non-ionic surfactants ${ }^{(2,17)}$. Above and beyond the interfacial composition, the average oil droplet size also influences lipase activity. Studies have demonstrated that fine emulsions $(<1 \mu \mathrm{m})$ were hydrolysed by pancreatic lipase faster than coarse emulsions $(>20 \mu \mathrm{m})$ in vitro ${ }^{(48)}$ in both animals ${ }^{(49)}$ and human subjects ${ }^{(12,50,51)}$. In the present in vitro study, we first observed the behaviour of the emulsion provided to rats in gastrointestinal-like conditions. Results showed that the emulsified state was maintained even with large variations in $\mathrm{pH}$ (Fig. 1), suggesting that in vivo, the lipid-water interface may be preserved up to the intestine level. Thus, TAG of the emulsified oil may be hydrolysed faster by pancreatic lipase, resulting in an increased absorption of hydrolysed products. In contrast, in the case of flaxseed oil in the bulk phase, the interface must be created by the mechanical mixing in the stomach and intestine. Nevertheless, the in vitro hydrolysis of emulsified oil by pancreatic lipase showed that lipase activity was lower than that in the oil as a bulk phase (Fig. 3). This is in agreement with previous in vitro studies showing that long-chain TAG emulsified with PL were not hydrolysed by pancreatic lipase, even in the presence of BS and colipase $^{(52-55)}$. However, it has been reported that this inhibition by PL disappeared due to the presence of NEFA generated by TAG hydrolysis ${ }^{(54,55)}$ that modified the interface properties. The efficiency of intestinal absorption is also determined by the solubilisation of hydrolysis products into BS-mixed micelles. In vitro micellisation experiments involving flaxseed oil (both emulsified and non-emulsified) demonstrated that a lower amount of surfactants was required to produce mixed micelles with the emulsion system (Table 3). In the case of rats that were fed emulsion, the additional amount of lysophospholipids indirectly provided by the dietary lipid formulation may facilitate the transport of hydrolysis products through the unstirred water layer of enterocytes. The present in vivo results suggested that the emulsification of flaxseed oil enhances its digestibility, due to the faster hydrolysis of TAG because of the pre-existing oil-water interface and a better solubilisation of hydrolysis products in mixed micelles. Consequently, emulsions may be less prone to 
oxidative degradation and may reside less long in the intestinal lumen, leading to a reduction of the extent to which they are conveyed to faeces. Besides parameters influencing lipid bioavailability in the intestinal lumen, it is worth noting that lipid recovery in the lymph may also be affected by the processes occurring in the enterocytes, i.e. uptake into the mucosal cells, as well as the packaging and secretion of chylomicrons. The supply of dietary phosphatidylcholine may favour the formation of chylomicrons ${ }^{(56)}$ and/or be involved in the regulation of jejuna apo A-I synthesis in animals ${ }^{(57)}$. Indeed, Nishimukai \& Hara ${ }^{(56)}$ have demonstrated that the amount of TAG in the rat lymph increased twofold in the presence of soya lecithin.

Several studies have pointed out that the fatty acid composition of chylomicrons and fatty acid distribution in TAG reflected that of the dietary oil ${ }^{(58-60)}$. It is well established that fatty acids esterified at the $s n-2$ position of dietary TAG are mainly retained during the absorption process $^{(61)}$ due to the positional specificity of pancreatic lipase. After incorporation of these hydrolysis products into the mucosal pool, most of the $2-\mathrm{MAG}$ are reacylated to TAG that are incorporated into chylomicrons secreted into the lymph. To our knowledge, no similar studies have been performed with flaxseed oil. ALA enrichment in chylomicrons was observed irrespective of the dietary form of flaxseed oil (Table 5). However, the percentage of ALA esterified at the $s n$ - 2 position of chylomicron TAG was slightly lower (18 and $23 \%$ for oil and emulsion, respectively) compared with that in dietary flaxseed oil (28\%). This may be attributed to a degradation of some 2 -monolinolenate glycerols ${ }^{(62)}$. Indeed, chylomicron TAG contained a high percentage of endogenous fatty acids, which were supplied by bile lipids, especially $16: 0,18: 1$ and $18: 2$ fatty acids ${ }^{(63,64)}$.

On the whole, the present results showed that the extent of fatty acid absorption, and especially of ALA, was significantly higher in the rat group ingesting emulsified oil compared with the group given oil in the non-emulsified state. Moreover, the results of the in vitro studies dealing with emulsion stability, lipid hydrolysis and solubilisation were used to interpret, at least partly, the increased lymphatic concentration in ALA in the newly synthesised TAG. Nevertheless, basic information on ALA bioavailability from flaxseed oil is still necessary to understand its biological efficiency. In particular, because the intramolecular fatty acid distribution in chylomicron TAG did not exactly reflect that of the dietary oil, the metabolic pathway of ALA during the digestion process remains to be further explored.

\section{Acknowledgements}

The authors acknowledge the National Association of Technical Research and the Aquitaine Regional Council for their financial support through a $\mathrm{PhD}$ research grant for L. C. The authors state that there are no conflicts of interest. Contribution made by each author to the research is as follows: L. C. is a PhD student who contributed to the design of the in vitro and in vivo experiments. C. B.-V. is the industrial $\mathrm{PhD}$ supervisor, specialist in lipid metabolism. L. F., E. M. and S. D. provided technical assistance for the lipid analysis. N. C. is an expert in lipid metabolism who helped to interpret the in vivo results. M. C. is the institutional PhD supervisor and is an expert in the formulation of colloidal systems for nutritional applications and in lipid bioavailability.

\section{References}

1. Embleton JK \& Poutonb CW (1997) Structure and function of gastro-intestinal lipases. Adv Drug Deliv Rev 25, 15-32.

2. Singh H, Ye A \& Horne D (2009) Structuring food emulsions in the gastrointestinal tract to modify lipid digestion. Prog Lipid Res 48, 92-100.

3. Kubow S (1996) The influence of positional distribution of fatty acids in native, interesterified and structure-specific lipids on lipoprotein metabolism and atherogenesis. $J$ Nutr Biochem 7, 7530-7541.

4. Ikeda I, Sasaki E, Yasunami H, et al. (1995) Digestion and lymphatic transport of eicosapentaenoic and docosahexaenoic acids given in the form of triacylglycerol, free acid and ethyl ester in rats. Biochim Biophys Acta 1259, 297-304.

5. Ramírez M, Amate L \& Gil A (2001) Absorption and distribution of dietary fatty acids from different sources. Early Hum Dev 65, S95-S101.

6. Mekki N, Charbonnier M, Borel P, et al. (2002) Butter differs from olive oil and sunflower oil in its effect on postprandial lipemia and triacylglycerol-rich lipoproteins after single mixed meals in healthy young men. J Nutr 132, 3642-3649.

7. $\mathrm{Mu} \mathrm{H} \&$ Porsgaard T (2005) The metabolism of structured triacylglycerols. Prog Lipid Res 44, 430-448.

8. Bach AC \& Babayan VK (1982) Medium-chain triglycerides: an update. Am J Clin Nutr 36, 950-962.

9. Marten B, Pfeuffer M \& Schrezenmeir J (2006) Medium-chain triglycerides. Int Dairy J 16, 1374-1382.

10. McClements JD \& Li Y (2010) Structured emulsion-based delivery systems: controlling the digestion and release of lipophilic food components. Adv Colloid Interface Sci 159, 213-228.

11. Cansell M, Nacka F \& Combe N (2003) Marine lipid-based liposomes increase in vivo fatty acid bioavailability. Lipids 38, 551-559.

12. Armand M, Pasquier B, André M, et al. (1999) Digestion and absorption of 2 fat emulsions with different droplet sizes in the human digestive tract. Am J Clin Nutr 70, 1096-1106.

13. Nishimukai M, Hara H \& Aoyama Y (2003) Enteral administration of soyabean lecithin enhanced lymphatic absorption of triacylglycerol in rats. Br J Nutr 90, 565-571.

14. Michaslki MC, Briard V, Desage M, et al. (2005) The dispersion state of milk fat influences triglyceride metabolism in the rat. ${ }^{13} \mathrm{CO}_{2}$ breath test study. Eur J Nutr 44, 436-444.

15. Michaslki MC, Soares V, Lopez M, et al. (2006) The supramolecular structure of milk fat influences plasma triacylglycerols and fatty acid profile in the rat. Eur J Nutr 45, 215-224.

16. Garaiova I, Guschina IA, Plummer SF, et al. (2007) A randomised cross-over trial in healthy adults indicating improved absorption of omega-3 fatty acids by pre-emulsification. Nutr J 6, 1-9.

17. Mun S, Decker EA \& McClements DJ (2007) Influence of emulsifier type on in vitro digestibility of lipid droplets by pancreatic lipase. Food Res Int 40, 770-781. 
18. Sandra S, Decker EA \& McClements DJ (2008) Effect of interfacial protein cross-linking on the in vitro digestibility of emulsified corn oil by pancreatic lipase. J Agric Food Chem 56, 7488-7494.

19. Bonnaire L, Sandra S, Helgason T, et al. (2008) Influence of lipid physical state on the in vitro digestibility of emulsified lipids. J Agric Food Chem 56, 3791-3797.

20. Legrand P, Astorg PO, Bougnoux P, et al. (2010) Avis de l'Agence française de sécurité sanitaire des aliments relatifs à l'actualisation des apport nutritionnels conseillés pour les acides gras (Opinion of the French agency for food, environmental and occupational health safety). AFSSA - Saisine no. 2006-SA-0359.

21. Astorg P, Arnault N, Czernichow S, et al. (2004) Dietary intakes and food sources of $n-6$ and $n-3$ PUFA in French adult men and women. Lipids 39, 527-535.

22. Combe N \& Boué C (2001) Apports alimentaires en acides linoléique et alpha linolénique d'une population d'Aquitaine (Dietary intakes of linoleic acid and alpha-linolenic acid in a population of Aquitaine). Oléag Corps Gras Lipides 8 , 118-121.

23. Cunnane SC, Ganguli S, Menard C, et al. (1993) High $\alpha$-linolenic acid flaxseed (Linurn usitatissimum): some nutritional properties in humans. Br J Nutr 69, 443-453.

24. Wallace FA, Miles EA \& Calder PC (2003) Comparison of the effects of flaxseed oil and different doses of fish oil on mononuclear cell function in healthy human subjects. Br J Nutr 89, 679-689.

25. Austria JA, Richard MN, Chahine MN, et al. (2008) Bioavailability of alpha-linolenic acid in subjects after ingestion of three different forms of flaxseed. J Am Coll Nutr 27, 214-221.

26. Bloedon LT, Balikai S, Chittams J, et al. (2008) Flaxseed and cardiovascular risk factors: results from a double blind, randomized, controlled clinical trial. J Am Coll Nutr 27, 65-74.

27. AFSSA (2006) Avis de l'Agence française de sécurité sanitaire des aliments relatif à l'évaluation de l'emploi de l'huile de lin, nature ou en mélange, dans l'alimentation courante ainsi que de son intérêt nutritionnel en matière d'apport d'acide alphalinolénique (Opinion of the French agency for food, environmental and occupational health safety on the use of flaxseed oil, pure or mixed with other oils, in current foods and on its nutritional impact relative to alpha linolenic acid supply). AFSSA - Saisine no. 2004-SA-0409.

28. AFSSA (2009) Avis de l'Agence française de sécurité sanitaire des aliments relatif à une demande d'évaluation des risques liés à la consommation courante d'huile de lin vierge (Opinion of the French agency for food, environmental and occupational health safety on the potential risks linked to the current consumption of virgin flaxseed oil). AFSSA - Saisine no. 2008-SA-0392.

29. Wolff RL, Combe N \& Entressangles B (1984) Incorporation et élimination de l'acide élaïdique dans les différents phospholipides des mitochondries ou leurs membranes chez le rat (Incorporation and elimination of elaidic acid in various phospholipids of mitochondria and their membranes in rats). Rev Fse Corps Gras 31, 161-170.

30. Ames BN (1966) Assay of inorganic phosphate, total phosphate and phosphatase. Meth Enzymol 18, 115-118.

31. Nacka F, Cansell M \& Entressangles B (2001) In vitro behavior of marine lipid-based liposomes. Influence of $\mathrm{pH}$, temperature, bile salts and phospholipase $\mathrm{A}_{2}$. Lipids $\mathbf{3 6}$, 35-42.

32. Hope A \& Theimer R (1996) Titrimetric test for lipase activity using stabilized triolein emulsions. Phytochemistry 42, 973-978.

33. Lichtenberg D (1985) Characterization of the solubilization of lipid bilayers by surfactants. Biochim Biophys Acta 821, $470-478$
34. Paternostre MT, Roux M \& Rigaud JL (1988) Mechanisms of membrane protein insertion into liposomes during reconstitution procedures involving the use of detergents. I. Solubilization of large unilamellar liposomes (prepared by reverse-phase evaporation) by Triton X-100, octyl glucoside and sodium cholate. Biochemistry 27, 2668-2677.

35. Bollman JL, Cain JC \& Grindlay JH (1948) Techniques for the collection of lymph from the liver, small intestine, or thoracic duct of rat. J Lab Clin Med 33, 1349-1352.

36. Combe N, Constantin MJ \& Entressangles B (1981) Lymphatic absorption of nonvolatile oxidation products of heated oils in the rat. Lipids 16, 8-14.

37. Lepage G \& Roy CC (1984) Improved recovery of fatty acid through direct transesterification without prior extraction or purification. J Lipid Res 25, 1391-1396.

38. Desnuelle P (1961) Pancreatic lipase. Adv Enzymol Relat Subj Biochem 23, 129-161.

39. Entressangles B, Sari H \& Desnuelle P (1966) On the positional specificity of pancreatic lipase. Biochem Biophys Acta 125, 597-600.

40. Lichtenberg D, Zilberman Y, Greenzaid P, et al. (1979) Structural and kinetic studies on the solubilization of lecithin by sodium deoxycholate. Biochemistry 18, 3517-3525.

41. Walter A, Vinson PK, Kaplun A, et al. (1991) Intermediate structures in the cholate-phosphatidylcholine vesicle-micelle transition. Biochem J 60, 1315-1325.

42. Hofmann AF \& Mysels KJ (1992) Bile acid solubility and precipitation in vitro and in vivo: the role of conjugation, $\mathrm{pH}$, and $\mathrm{Ca}^{2+}$ ions. J Lipid Res 33, 617-626.

43. Mazer NA, Benedek GB \& Carey MC (1980) Quasielastic light-scattering studies of aqueous biliary lipid systems. Mixed micelle formation in bile salt-lecithin solutions. Biochemistry 19, 601-615.

44. Barcelo-Coblijn G, Murphy EJ, Othman R, et al. (2008) Flaxseed oil and fish-oil capsule consumption alters human red blood cell $n$-3 fatty acid composition: a multipledosing trial comparing 2 sources of $n-3$ fatty acid. $A m J$ Clin Nutr 88, 801-809.

45. Harper CR, Edward MC \& Jacobson TA (2006) Flaxseed oil supplementation does not affect plasma lipoprotein concentration on particle size in human subjects. J Nutr 136, 2844-2848.

46. Laugerette F, Vors C, Géloën A, et al. (2010) Emulsified lipids increase endotoxemia: possible role in early postprandial low-grade inflammation. J Nutr Biochem (Epublication ahead of print version 19 March 2010).

47. Jiang Y, Noh SK \& Koo SI (2001) Egg phosphatidylcholine decreases the lymphatic absorption of cholesterol in rats. J Nutr 131, 2358-2363.

48. Borel P, Armand M, Ythier P, et al. (1994) Hydrolysis of emulsions with different triglycerides and droplet sizes by gastric lipase in vitro. Effect on pancreatic lipase activity. $J$ Nutr Biochem 5, 124-133.

49. Borel P, Armand M, Ythier P, et al. (1994) Digestion and absorption of tube-feeding emulsions with different droplet sizes and compositions in the rat. $J$ Parenter Enteral Nutr 18, $534-543$.

50. Armand M (2007) Lipases and lipolysis in the human digestive tract: where do we stand? Curr Opin Clin Nutr Metab Care 10, 156-164.

51. Carrière F, Renou C, Lopez V, et al. (2000) The specific activities of human digestive lipases measured from the in vivo and in vitro lipolysis ot test meals. Gastroenterology 119, 949-960.

52. Borgström B (1980) Importance of phospholipids, pancreatic phospholipase $\mathrm{A}_{2}$, and fatty acid for the digestion of dietary fat: in vitro experiments with porcine enzymes. Gastroenterology 78, 954-962. 
53. Reis P, Holmberg K, Watzke H, et al. (2009) Lipases at interfaces: a review. Adv Colloid Interface Sci 147-148, 237-250.

54. Patton JS \& Carey MC (1981) Inhibition of human pancreatic lipase-colipase activity by mixed bile salt-phospholipid micelles. Am J Physiol 241, 328-336.

55. Larsson A \& Erlanson-Albertsson C (1986) Effect of phosphatidylcholine and free fatty acids on the activity of pancreatic lipase-colipase. Biochem Biophys Acta 876, 543-550.

56. Nishimukai M \& Hara H (2007) Soybean phosphatidylcholine-induced enhancement of lymphatic absorption of triglyceride depends on chylomicron formation in rats. Biosci Biotechnol Biochem 71, 1192-1197.

57. Wang H, Du J, Lu S, et al. (2001) Regulation of intestinal apolipoprotein A-I synthesis by dietary hosphatidylcholine in newborn swine. Lipids 36, 683-687.

58. Lambert MS, Botham KM \& Mayes PA (1996) Modification of the fatty acid composition of dietary oils and fats on incorporation into chylomicrons and chylomicron remnants. Br J Nutr 76, 435-445.
59. Ikeda I, Yoshida H \& Imaizumi K (1997) Effects of triolein or oleic acid on lymphatic recovery of docosahexaenoic acid given as ethyl ester and their intramolecular distribution in lymph triglyceride of rats. Lipids 32, 949-952.

60. Yoshida H, Mawatari M, Ikeda I, et al. (1999) Effect of dietary seal and fish oils on triacylglycerol metabolism in rats. J Nutr Sci Vitaminol 45, 411-521.

61. Hunter JE (2001) Studies on effects of dietary fatty acids as related to their position on triglycerides. Lipids $\mathbf{3 6}$, 655-668.

62. Christensen M \& Hoy CE (1996) Effect of dietary triacylglycerol structure on triacylglycerols of resultatnt chylomicrons from fish oil- and seal oil-fed rats. Lipids 31, 341-344.

63. Shrivastava BK, Redgrave TG \& Simmonds WJ (1967) The source of endogenous lipid in the thoracic duct lymph of fasting rats. QJ Exp Physiol 52, 305-312.

64. Baxter JH (1966) Origin and characteristics of endogenous lipid in thoracic duct lymph in rats. J Lipid Res 7, 158-166. 